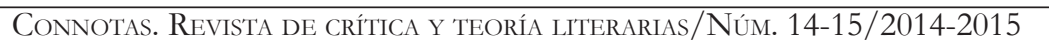

\title{
Un epílogo de La ventana indiscreta. Una poética materialista del cine
}

\author{
Pablo Huerga Melcón*
}

Resumen:

Basado en el sistema del español Gustavo Bueno, el materialismo filosófico, el autor ha llevado a cabo una sistematización de lo que para él es el cine, que examina en su especificidad, todo ello bajo la óptica de una interpretación de la Poética de Aristóteles que se aleja de lo habitual, desde que revisa los roles de la materia y de la forma en la obra artística. El presente artículo constituye un epílogo de su libro de reciente publicación, La ventana indiscreta (2015), para abundar y profundizar en torno a un problema que se remite no solo al cine, sino a las artes en general y su relación con las maneras de entender lo científico. Así, se presenta al cine como un artefacto que no solo está al servicio de la representación de determinadas realidades, sino que además contribuiría a la construcción del mundo tal y como lo entendemos. Los debates entre la ética y la moral tendrían en el cinematógrafo un elemento capaz de poner en perspectiva lo que se entiende por verdad en varios contextos, algo que lleva a contrastar los objetivos y capacidades de la poética frente a la estética, en tanto que no sería la belleza, así como tampoco la utilidad, el criterio idóneo para discutir a propósito del engranaje del cine y las artes que lo complementan.

Palabras clave:

Cinematógrafo, estética, poética, ciencia y arte.

* IES Rosario de Acuña, Gijón. 
El libro La ventana indiscreta, editado por la editorial Rema y Vive en mayo de este año en Gijón, aborda el cine tomando como referencia el análisis que Aristóteles hizo de la tragedia en su Poética. Entendemos que la Poética es la disciplina filosófica que analiza las artes desde la perspectiva gnoseológica, y no meramente epistemológica; no en tanto que las artes "son vistas" por los sujetos, sino en cuanto son categorías de la realidad, constituidas, por tanto, por partes materiales y partes formales; y define el campo gnoseológico de estas categorías artísticas de modo preciso. La Poética, a diferencia de la Estética (Baumgarten, Kant), analiza las obras de arte como realidades objetuales, artefactos que simulan miméticamente la realidad, analizan y estudian críticamente el mundo, y contribuyen a su transformación (Bueno, Música). La Poética analiza las obras de arte en lo que tienen que ver con la verdad; por ello decimos que la Poética es la gnoseología de las artes miméticas y consideramos que puede ser organizada a partir de la teoría del cierre categorial del filósofo español Gustavo Bueno.

En la Poética, Aristóteles analizaba la tragedia (Bueno, Individuo). Nosotros analizamos, desde la poética materialista del cierre categorial, el cine. Y tomamos de la obra de Aristóteles tres ideas clave: la primera, la afirmación según la cual la poesía sería más científica (o filosófica, según las diversas traducciones) que la historia; la segunda, su teoría de que las artes miméticas son los medios a través de los cuales se "representa" una sola acción; y la tercera, la idea de que esta acción debe quedar representada a partir de un esquema ternario compuesto de planteamiento, nudo y desenlace.

Las tres cuestiones contribuyen decisivamente a delimitar el campo gnoseológico de las artes miméticas, frente a otras ciencias como la Historia, la Sociología, Psicología, Biología, Etología, etc. Aristóteles ya ofreció la clave para determinar el campo gnoseológico de la Poética, puesto que dice que representa acciones; y particularmente una sola acción. Así pues, las artes miméticas estudian las acciones en presente dramático y, por tanto, ese estudio necesariamente exige que las acciones sean representadas: representar es la forma de estudiar las acciones en su propio acontecer dramático. Pero las acciones operatorias (humanas o animales) son acciones esencial- 
mente finalistas. Esta es la razón por la que Aristóteles prescribe que toda representación poética debe incluir un planteamiento, un nudo y un desenlace, porque toda acción finalista tiene un planteamiento inicial, un despliegue de la finalidad en el tiempo y una conclusión que tiene que ver con la consecución del fin planteado al inicio. Así, no es la belleza, ni la utilidad, ni ningún otro criterio ad hoc el que define lo que son las artes llamadas bellas, sino su campo material de estudio, y la manera particular de estudiarlo que dicho material exige. La poética es la gnoseología de las acciones finalistas en presente dramático.

Así, delimitamos el campo de estudio de las artes miméticas, frente a las artes mecánicas: las artes miméticas son distintos medios de representación de las acciones finalistas en su propio acontecer dramático, y esto las distingue del resto de las artes técnicas. Ello permite incorporar nuevas técnicas de representación de esas mismas acciones, como el cine, la televisión, los videojuegos o, incluso la propia robótica, porque, bien mirado, la robótica es el arte de recrear por medios mecánicos una acción en presente dramático, poner en movimiento finalista un artefacto técnico. Tal vez la robótica podría considerarse el límite objetivo de la poética.

\section{Una nueva acepción de ciencia: las ciencias miméticas}

Hasta prácticamente el siglo XIX las ciencias humanas también permanecieron fuera del ámbito de las categorías científicas. Solo una comprensión más amplia de las funciones gnoseológicas de las ciencias permitió incorporar estas disciplinas al ámbito más general de las ciencias, hasta el punto de que en la teoría del cierre categorial se habla de cuatro acepciones de las ciencias en un despliegue histórico. ${ }^{1}$ La primera corresponde con la ciencia como "saber hacer", un concepto según el cual "la ciencia se mantiene aun muy próxima

\footnotetext{
${ }^{1}$ Sobre estas cuatro acepciones puede consultarse Bueno, ¿Qué es la ciencia? (especialmente la primera parte).
} 
a lo que entendemos - dice Bueno-, por 'arte', en su sentido técnico". La segunda acepción, procedente de Aristóteles, entiende la ciencia como sistema ordenado de proposiciones derivadas de principios, una acepción que se extiende hasta prácticamente la revolución científica, momento en el que se abre paso una tercera acepción de ciencia como ciencia positiva, tal y como se despliegan las ciencias a partir de ese momento. Una cuarta acepción recoge la visión de la ciencia que se abre paso a través de la irrupción de las ciencias humanas, muchas veces también consideradas como un tipo de arte. En este sentido, tal vez podría pensarse que ya es hora de que entendamos y rescatemos las categorías del hacer propias de la primera acepción de ciencia, como un entramado de ciencias particular, que deberá quedar incorporado como una nueva acepción de ciencia, la quinta, más abierta y organizada con criterios y planteamientos gnoseológicos más audaces.

\section{Consideraciones sobre la mímesis}

En nuestro libro proponemos una interpretación de la teoría de la mímesis aristotélica, la teoría que de un modo u otro ha estado protagonizando todos los debates acerca del arte, sin que se haya conseguido establecer ni una convincente discriminación entre las artes mecánicas y las llamadas bellas artes, y sin que se hayan podido establecer los grados de involucración de las artes en el marco general de las categorías del hacer, y de las categorías científicas. La propuesta del libro es reconstruir esta teoría para determinar el lugar que ocupan las artes miméticas en el marco general del debate sobre la teoría del arte y determinar el alcance de estas categorías del hacer en cuanto formas de conocimiento del mundo.

Frente a la teoría tradicional de la mímesis, ahora el arte no es la forma que recrea una materia o "contenido" o "argumento", como se suele decir (a veces incluso con cierto desprecio, sobre todo cuando se hace una defensa radical del arte como forma que renuncia a los contenidos, a los argumentos, etc.). Antes bien, si la acción en presente dramático es lo que hay que mimar (Adrados), 
lo que ocurre es que los argumentos dramáticos son precisamente las partes formales de la acción, mientras que las diferentes artes son necesariamente los distintos medios a través de los cuales dialécticamente se despliega la acción.

En un ejército, o una batalla, como la que tiene lugar en Espartaco, de Kubrick, por ejemplo, tenemos unas partes materiales compuestas por toda una serie de figuras, hombres, armas, pertrechos, en un entorno material escénico determinado. Lo que convierte ese "amontonamiento" de cosas de la vida (expresión de Sklovski) en un ejército, en una batalla concreta, es el orden definido de los objetos, la disposición escénica finalista que organiza las partes en un todo articulado, un ejército en batalla. Esta misma situación por analogía ocurre en todas las artes. Cuando Lessing distingue entre pintura y poesía, dice que la pintura lo que hace es yuxtaponer una serie de objetos en el plano, mientras que la poesía sería la acción que esos objetos realizan en el tiempo, entendida como las transformaciones en las relaciones que median entre esos cuerpos: objetos y sujetos operatorios. La pintura representa la acción por la ordenación instantánea de cuerpos yuxtapuestos en un instante que permite reconstruir lo anteriormente acontecido, y lo posterior. De ahí que en pintura y fotografía se discuta siempre acerca del momento crucial, el momento "más pregnante" que permitirá comprender la acción hacia atrás y hacia delante. En escultura, las partes formales serán los propios cuerpos en su gesticulación, la pose; en ellos, lo fundamental es el gesto que organiza las partes atributivas del cuerpo, y no su material técnico (bronce, madera, etc.). No podemos confundir la configuración técnica del bronce en cuerpo, con la configuración de las partes del cuerpo en una acción determinada, que es lo constitutivo del arte mimético. En el cuadro de Picasso, el Guernica, los elementos adquieren una unidad dramática cuando se entiende la acción que los organiza en una totalidad sistemática. El cierre categorial del Guernica como teorema de la Pintura viene dado por la articulación de todas sus partes en la unidad de acción que totaliza la yuxtaposición de elementos en una unidad narrativa: la adoración de los pastores después del bombardeo nazi-fascista (esta tesis la desarrollamos en un ensayo de 2008 titulado "La otra cara del Guernica", que puede 
consultarse en Internet). En literatura, el escenario material no vendrá dado por la disposición de palabras, como un enfoque técnico exigiría, sino que el escenario de la acción son los distintos estilos literarios, que adquieren orden y estructura cuando a través del estilo se recrea una acción. La acción permite dar forma narrativa al estilo literario, el cual, sin dicha acción, sería simplemente vacío, un amontonamiento de técnicas de escritura sin sentido.

\section{Sobre la delimitación entre artes técnicas y artes bellas}

Las artes miméticas, así las llama Aristóteles, son las artes que suelen catalogarse como bellas artes, poesía, pintura, escultura, arquitectura o música. Pero al hablar de artes miméticas, solo podemos seguir una denotación de su extensión a partir del hecho de que según la interpretación tradicional estas artes copian la realidad, son formas que interpretan y "reflejan" de modo "artístico" la realidad. La realidad copiada se entiende pues como el contenido, la materia, del arte, y las artes las distintas formas de representación de la realidad. Esa es la doctrina tradicional. Según esta definición, las artes son formas, y en cuanto reflejos de la realidad, se produce una especie de dualismo ontológico entre la materia, por un lado, y la forma, por otro. Tal ha sido la situación que cuando los artistas defienden la completitud ontológica de la obra de arte, acaban siendo acusados de formalistas, es decir, de renunciar finalmente a los contenidos, a la materia.

Sin embargo, esta noción procede de una confusión arraigada en la teoría de las cuatro causas aristotélicas, que da por hecho la existencia de una causa formal y una causa material en todo proceso productivo, poiético, técnico. Ahora bien, si todo arte se entiende como la composición de una materia por una forma, entonces las artes miméticas se entienden simplemente como unas técnicas particulares que partiendo de las formas construyen objetos artísticos como otro artesano construye zapatos y otro sillas, por ejemplo. El escultor toma una materia, el bronce, la arcilla y con ella como materia aplica una forma y construye una obra de arte. Visto así, entre la obra de arte y cualquier otro "artefacto técnico" hecho de bron- 
ce o arcilla solo podemos interponer otro criterio subjetivo más, por ejemplo, la belleza, el gusto, etc., para discriminar un artefacto técnico productivo y otro propiamente artístico. Ello convierte al sujeto receptor en el juez subjetivo de una obra técnica como arte y reduce toda la discusión de las artes a mera estética, que es como se ha entendido (así Kant o Baumgarten), es decir, como una cuestión meramente epistemológica, que estaría en función de la percepción que del objeto tiene el sujeto. De esta forma las artes bellas se distinguen por un criterio ad hoc, la belleza, que en rigor es una propiedad que cabe atribuir a cualquier objeto técnico; otro criterio que suele usarse es la utilidad, por ejemplo, de manera que se podrá discutir sobre si las artes miméticas son útiles o inútiles, etc. Desde luego, cualquier intento de discriminar así el campo gnoseológico de las artes miméticas resulta impracticable.

\section{Mímesis como recreación en presente dramático de acciones finalistas}

Sin embargo, si leemos con detenimiento la Poética de Aristóteles, el planteamiento es realmente diverso al que suele utilizarse para hablar de las artes, y nos permitiría explorar una ruta totalmente diferente acerca de las artes. Lo que dice Aristóteles en la Poética es que las artes miméticas lo que hacen es copiar acciones, es decir, no tanto reflejarlas, como recrear las acciones, esto es, mimarlas, tal y como hacen los actores en el teatro, o en el cine, por ejemplo. Y esta recreación se llama mímesis no tanto porque se trate de alcanzar un reflejo de la realidad, como se suele entender de modo grosero, sino porque esta recreación se mima, es decir, se representa en presente dramático, en cuanto se está realizando la acción. La mímesis, como advierte Adrados en su libro, Fiesta, comedia y tragedia, es ante todo, mimo, mimar acciones, recrearlas en su acontecer en presente dramático. Y este sería precisamente el cometido de todas las artes bellas, la recreación en presente dramático de una acción (así, si ello es bello o útil es una cuestión secundaria, porque igualmente podemos discutir acerca de la belleza de cualquier artefacto técnico o de 
su inutilidad relativa, etc.).

Ahora bien, si tomamos en consideración esta teoría de la mímesis, y de las artes miméticas, como recreación en presente dramático de una acción, entonces se entiende también otra idea que está presente en la Poética de Aristóteles, y que da una imagen totalmente diferente de las artes, porque allí dice Aristóteles que las artes miméticas son, en realidad, los medios a través de los cuales se pone en presente dramático una acción. Es decir que las artes no son las formas sino las materias, los medios que permiten la recreación de la acción. Una acción que además no puede entenderse de cualquier manera, sino en el siguiente sentido: debe ser única la acción y debe estar presidida por los principios de "planteamiento", "nudo" y desenlace". Este precepto aristotélico no es una norma arbitraria que pretende imponer Aristóteles en la tragedia, como se suele pensar, sino, al contrario, es la manifestación de la propia esencia de la acción en presente dramático, porque lo que esta norma indica es que cuando Aristóteles habla de acción se refiere a una acción finalista, esto es, a una acción que nace de la propia prolepsis de los sujetos, que se proponen fines, y en cuanto que esos fines lo son, se despliegan como planes y programas a desarrollar diegéticamente en el tiempo, en conflicto con otros fines de otros sujetos y en conflicto con el medio escénico en el que debe transcurrir la acción necesariamente. Por tanto, la recreación en presente dramático debe serlo de una acción finalista en conflicto.

De esta manera, sorprendentemente, tenemos ya delimitado el marco gnoseológico de las artes miméticas, frente a las artes mecánicas: las artes miméticas son distintos medios de representación de las acciones finalistas en su propio acontecer dramático, y esto las distingue del resto de las artes técnicas, y permite incorporar nuevas técnicas de representación de esas mismas acciones, como el propio cine, aunque Aristóteles no lo haya conocido, o la televisión, o los videojuegos, o, como hemos dicho anteriormente, la propia robótica. 


\section{Partes materiales y formales en el cine}

En el cine, la constatación de las partes formales es muy apreciable a través de los estudios realizados acerca del despliegue de los argumentos en diferentes escenarios (Balló, Gubern, etc.). Cómo una misma historia se desarrolla y adquiere un sentido único cuando se ubica en un determinado escenario frente a otros. Un entorno escénico puede dar lugar al despliegue de diferentes acciones que son, a su vez, distintas historias. De manera que las partes materiales adquieren sentido cuando se articulan a través de las acciones finalistas. Constatamos, por ejemplo, una coincidencia argumental entre una película como Casablanca de Michael Curtiz, y La diligencia de John Ford. Cada una en un entorno escénico diferente permi-

te construir una historia única, por la articulación dialéctica de los componentes formales con los distintos objetos. El entorno escénico es, por tanto, esencial, constitutivo, en la configuración de la acción y confiere a la acción una identidad y unidad que le da un sentido único. $\mathrm{Al}$ mismo tiempo, una acción sin escenario es imposible ontológicamente.

Partiendo de esta teoría, La ventana indiscreta ofrece un despliegue sistemático del campo cinematográfico mediante el cruce de los distintos entornos escénicos y de acción dramática. (Remitimos al lector a revisar el cuadro sistemático que organiza todos los géneros cinematográficos a partir de los criterios gnoseológicos aquí expuestos, para evitar prolijidad en el presente artículo).

\section{La obra de arte como simulación mimética}

En definitiva, podemos considerar el cine como un arte mimético que lejos de reflejar la realidad la recrea, la construye y contribuye a su transformación. El cine es, pero también cualquier arte mimética, una simulación mimética, como ha dicho Bueno (Televisión) otras veces. Ahora bien, una simulación lejos de alejarnos de la realidad, puede ser la mejor manera de poder analizarla y comprenderla. Las artes miméticas simulan la realidad de la acción mimética y en esa 
simulación permiten comprenderla de un modo más complejo. Toda obra de arte es, en este sentido, un análisis de la acción en presente dramático, desde sus propias categorías, que vienen a ser los estilos de cada arte mimética.

Las artes analizan la realidad tal y como se presenta a la escala de los cuerpos operables, y de los sujetos operatorios, a escala, como dice Bueno, apotética, a la escala en la que se conforma el vaciado de cuerpos materiales interpuestos que permiten configurar acciones prolépticas a distancia entre objetos, un vaciado que sería imposible a escala física, por ejemplo, porque toda percepción se construye a través de la presencia "invisible" pero real, paratética, de una realidad material: masas de fotones que conforman sin embargo nuestra percepción. ${ }^{2}$ Las artes analizan el mundo a la escala de nuestras operaciones y las representan en el entorno material escénico corpóreo que configura el despliegue de los escenarios en la historia. Pero esa escala no agota la realidad, al contrario. Diríamos que la escala del análisis de las acciones finalistas en presente dramático constituye un campo categorial suficientemente preciso porque desde él es imposible reconstruir, por ejemplo, la Historia; porque la Historia tiene que integrar esas acciones finalistas en un marco de explicaciones causales que desbordan los límites del propio análisis de las acciones (Bueno, Individuo). Por más que analicemos las acciones finalistas particulares en su despliegue dramático en conflicto, no podemos reconstruir las líneas causales y las propias teorías históricas. Tan importantes son para la Poética los héroes como los muertos, más la venganza de Ulises, que la restauración de la monarquía en Ítaca, más Príamo llorando por su hijo Héctor muerto, que el fin de Troya por los griegos. Puede interesarse por el sufrimiento de un soldado nazi en Stalingrado y menos por la derrota del nazismo. Esta circunstancia es la que hace siempre un tanto odiosa a la Poética, porque fácilmente puede

\footnotetext{
${ }^{2}$ Sobre estas cuestiones relacionadas con la teoría del hiperrealismo de Gustavo Bueno, puede consultarse el tercer tomo de la Teoría del cierre categorial, así como Huerga, "Breviario".
} 
orientarse hacia la legitimación ideológica de perspectivas políticas indeseadas, lo que inclinó a Platón al convencimiento de que la poesía es mejor mantenerla alejada de una ciudad bien gobernada. Salvo cuando se entiende la Poética como fuente de toda moral, en cuyo caso estamos ante la presencia de esas figuras heroicas que tanto nos gustan. Así, la Poética es solidaria de la perspectiva ética, mientras que la Historia lo es más de la moral ${ }^{3}$. A la poética le interesa el individuo abstracto; a la Historia, las clases sociales, los Estados, las naciones y los reyes, dicho grosso modo.

\section{Hacia una gnoseología de las artes}

¿Pero, cabe hablar de verdades en las artes? ¿Cabe hablar de verdad gnoseológica en el cine? Porque Aristóteles llegó a decir que la Poética es más "científica" que la historia, o más "filosófica", dependiendo de la traducción. En cualquier caso, es necesario reconocer, como hace Bueno, que la poética es evidentemente el germen técnico de la historia, ${ }^{4}$ porque al fin y al cabo, aunque desde las acciones particulares no podemos reconstruir las leyes históricas, sí es necesario reconocer que estas leyes históricas solo pueden darse a través de esas acciones particulares en presente dramático. Pero son irreductibles. De la misma manera que la Biología no explica la acción dramática, pero la fundamenta. O la Física.

Desde luego, si partimos de la teoría de la mímesis como copia o reflejo de la realidad, sería imposible analizar la cuestión de la verdad en el cine y en las artes en general. Tradicionalmente, la teoría del reflejo entenderá que las artes a veces copian, o simulan, pero que fundamentalmente "crean", o inventan, y por tanto, la imagina-

\footnotetext{
${ }^{3}$ Para una distinción clara entre ética y moral desde el materialismo filosófico debe consultarse la primera lectura, "Ética y moral y derecho", en Bueno, El sentido.

${ }^{4}$ Para este asunto, además de El individuo en la Historia, debe consultarse Bueno, "Reliquias".
} 
ción es libre y resulta de todo punto imposible hablar de verdades. Hasta tal punto pesa este criterio que incluso hablando de la televisión se llega a decir que la televisión solo es verdadera cuando es en directo, o como Gustavo Bueno la llama, "televisión formal". Desde el enfoque de la mímesis como copia formal de una realidad material o contenido, solo caben tres perspectivas acerca de la verdad del arte, tres opciones que podemos definir desde la teoría del cierre categorial como tres de las cuatro perspectivas gnoseológicas posibles, aunque el resultado es que desde ninguna de ellas podría hablarse de las artes como ciencias miméticas. ${ }^{5}$ Las tres opciones serían: 1. Que el cine copia la realidad y su verdad está en función de la capacidad de copiar la realidad concreta; esta opción la llamaremos el adecuacionismo, es decir, la adecuación entre la realidad concreta y la copia mimada determina la verdad de una película. Es evidente que desde esta perspectiva el cine nunca podrá entenderse como ciencia, puesto que muchas películas inventan, adaptan novelas, o simplemente "crean". 2. Por ello, la segunda opción posible es que el teoreticismo, esto es, la teoría que reconoce que en el arte y en las ciencias se crea formalmente, independientemente de la realidad, y solo cabrían trámites como el falsacionismo, que en el caso del arte podría ser considerado irrelevante. El artista crea y le trae sin cuidado si se puede falsar o no su creación con la realidad concreta. El arte es invención libre, imaginación, etc. 3. Frente a estas dos posturas, se perfila la última postura posible desde la noción tradicional de mímesis: aquella que defiende que la verdad del arte está en la misma realidad que no ha de ser si quiera copiada o mimada sino "vista" directamente. En el cine tenemos los ejemplos de Víctor Erice o Luís Guerín, quienes buscando superar la recreación mimética pretenden convertir el cine en testimonio, poético, magnífico, pero testimonio directo. Es el descripcionismo. Sin embargo, a nadie se le escapa que el intento descripcionista no deja de simular y recrear, de la misma manera que por más que se

\footnotetext{
${ }^{5}$ Para la cuestión general de los cuatro tipos básicos de teorías gnoseológicas puede consultarse el primer tomo de la Teoría del cierre categorial.
} 
quiera "crear" en el arte debe quedar algún resquicio comprensivo en lo que se hace si no se quiere que la obra de arte resulte ser una mera alucinación incomprensible, de manera que la opción teoreticista tampoco es viable en su pureza. Y, por otro lado, también constatamos que el adecuacionismo solo sirve para determinados casos y aun cuando pretendamos hacer un cine que recree la realidad concreta nunca lo hace completamente, y el director inventa y organiza la película conforme a criterios puramente estéticos o prácticos independientemente de si reproduce una determinada acción realmente existente, por así decir. En definitiva, ninguna de las tres perspectivas permite afrontar el cine como ciencia, esto es, en la medida en que se pueda analizar en él la verdad como un predicado necesario y no meramente accidental en algunas determinadas películas, como cuando en una película como Amanecer (Sunrise: A Song of Two Humans, EUA. 1927), de F. W. Murnau, se propone el siguiente texto al espectador:

Esta acción de un hombre y su esposa es de ningún lugar y de todos los lugares. Es posible escucharla en cualquier lugar y en cualquier hora. Pues donde quiera que el sol nace o se pone, en el tumulto de la ciudad o bajo el cielo abierto de la granja, la vida es muy semejante; a veces amarga y a veces dulce.

Lo mismo, pero al revés, ocurre en multitud de películas. Por señalar una reciente, en La isla mínima (España, 2014), de Alberto Rodríguez, por ejemplo, se advierte al final que "todo parecido con la realidad es mera coincidencia". Con ocasión de la entrevista que Radio Nacional de España le hizo a Wim Wenders, con ocasión de la presentación de su última película Todo saldrá bien (Every Thing Will Be Fine, Alemania| Canadá| Francia| Suecia| Noruega, 2015), contesta que eligió este tema porque "es algo que puede ocurrirle a cualquiera". 


\section{Hiperrealismo y circularismo}

Por tanto, vemos que en el cine existe una voluntad tradicional de realismo, de verdad, que constituye precisamente el fundamento de todo el desarrollo de sus técnicas narrativas y constructivas, la necesidad de resultar verosímil. En gran medida, se puede decir que la verosimilitud es un criterio de calidad cinematográfica; al menos para distinguir las películas de "serie B". Para entender las posturas teóricas de autores como André Bazín, para quien "el cine alcanza su plenitud al ser arte de lo real", que es un poco la idea que está detrás de la escuela de Víctor Erice; hay que echar mano de la teoría del hiperrealismo de Gustavo Bueno ${ }^{6}$ acerca de la percepción de la realidad. El hiperrealismo es el argumento que nos permite comprender el cine precisamente como una "ventana indiscreta", esto es: que lo que vemos en la pantalla grabado es tan verdadero como lo que podemos ver a través de una ventana. Las mismas ilusiones ópticas que sirven para producir un efecto visual determinado en el cine se repiten en la realidad cotidiana de nuestro mundus adspectabilis, y esta es la clave de todo el problema sobre la verdad gnoseológica del cine y de las artes en general. La verdad de una obra de arte no está en función de su adecuacionismo con lo real, porque toda obra de arte supone una recreación, una invención a partir de la imaginación, y porque es imposible para el arte una mera descripción. Solo un enfoque circularista que entiende la verdad como construcción permite afrontar el problema de la verdad del arte desde una perspectiva gnoseológica. ${ }^{7}$

Entendemos la dualidad mimética entre copia y realidad como un enfoque reduccionista y simplista del problema del arte. Si entendemos el arte como forma y la realidad representada o mimada, como materia, solo caben gnoseológicamente cuatro caminos posibles: entender la verdad como adecuación de la forma a la materia

\footnotetext{
${ }^{6}$ Tal como aparece desarrollada en la Teoría del Cierre Categorial, tomo 3.

${ }^{7}$ El circularismo, como doctrina gnoseológica, puede consultarse en la Teoría del cierre categorial (particularmente, el primer tomo).
} 
(lo que cabría hacer con el cine histórico, es el criterio vulgarmente aceptado para la verdad en el cine); reducción de la verdad a la forma (teoreticismo, comprensión del arte como forma, como creación, y concepción del artista como libre creador de la nada); reducción de la verdad a la materia (descripcionismo, documentalismo, que entiende el arte como testimonio). Ninguno de los caminos apuntados permite comprender la obra de arte, porque es imposible la adecuación perfecta, es imposible la creación de la nada y es imposible la descripción naturalista sin creación. En definitiva, la única opción que nos queda es disolver la dualidad materia y forma y comprender la obra de arte como una construcción dada en la misma realidad concreta y articulada en la misma realidad, como diría Sklovski. Las obras de arte son compuestos de partes materiales y formales, al igual que el resto de la realidad. Y su especificidad reside en lo que construyen y cómo lo construyen. El hiperrealismo nos permite comprender que una grabación cinematográfica es una realidad existente grabada, una simulación mimética como la que se puede producir en un reflejo de un escaparate al pasar caminando. Qué es lo que simulan las obras de arte: acciones finalistas en presente dramático. Y las artes son los medios de los que valen los artistas para recrear esas acciones finalistas: escultura, pintura, música, arquitectura, teatro, cine... Por tanto, las partes materiales y formales constitutivas de las obras de arte tienen que ver con esas mismas acciones finalistas. La verdad de una obra de arte consiste precisamente en la articulación de sus partes en una unidad con sentido finalista. Esta articulación de partes en un todo unitario es lo que permite al espectador comprender su significado, entender lo que dice como una unidad.

Por tanto, la verdad de una obra de arte es una identidad sintética procesual (Bueno, Estado), un cierre categorial que se alcanza cuando las partes constitutivas de la obra se articulan en una unidad dotada de sentido que permite comprender su articulación como una unidad finalista. Esa es la verdad del arte. La verdad de una escultura es la pose que se consigue con la acumulación de sus partes constitutivas en una unidad expresiva; la verdad de un relieve es la articulación de sus partes en una narración, como cuando en 
la Eneida se relata el episodio en que Eneas se encuentra en medio de un bosque con un templo cuyos relieves es capaz de interpretar como la narración de la propia guerra de Troya. La articulación de las partes en una unidad de sentido finalista está recogida en toda comprensión de cualquier obra de arte. Por ejemplo, el cuadro de El Guernica de Picasso lo hemos entendido así: el cierre categorial ${ }^{8}$ del cuadro se produce cuando el conjunto de elementos adquiere una unidad en función de la narración que construyen entre todos ellos: la adoración de los pastores de la Sagrada Familia después del bombardeo de los nazis en la guerra civil española. Heródoto cuenta que en la campaña de Darío contra los escitas estos le envían un presente consistente en una rata, un águila, una rana y unas flechas. Dos intérpretes analizan el presente. Uno le dice a Darío: "Los escitas entregan su agua, su tierra y sus armas". Otro intérprete le dice: "Los escitas advierten: si no sales de aquí, saltando el mar como una rana, huyendo como una rata o volando como los pájaros, seréis masacrados por nuestras flechas".

Así mismo, existen diversas narraciones posibles que se pueden construir a partir de la acumulación y organización de las partes materiales en función de las distintas finalidades. Por ello, podemos decir que existen partes materiales y formales en el cine, y en las artes en general. La organización de las diversas partes materiales en función de los fines permiten construir una verdad artística. Cada obra de arte es así un teorema, una unidad narrativa completa que constituye una unidad de sentido finalista, y esto es precisamente lo que permite discriminar una obra de arte de otra y entenderla como identidad y verdad. En el cine, por tanto, la verdad resulta de la verosimilitud conforme a la cual un conjunto de partes aparece articulado por una serie de acciones finalistas en conflicto. La posibilidad de estructurar y organizar un conjunto de partes en el tiempo capaz de recoger una unidad de sentido narrativo es pre-

\footnotetext{
${ }^{8}$ Sobre la cuestión de la verdad como identidad sintética debe consultarse el libro Teoría del cierre categorial, antes citado, ¿Qué es la ciencia?, también citado anteriormente o, por ejemplo, Bueno, La idea de ciencia.
} 
cisamente la verosimilitud de una narración cinematográfica. Ver cómo transcurre la acción finalista, cómo se despliega una acción o un conjunto de acciones finalistas en sus conflictos desde su planteamiento hasta sus resultados.

\section{Sobre cine propio e impropio}

En vez de hablar de cine verdadero cuando se adecúa a la realidad narrada, que es el modo tradicional de entender la cuestión en términos de la teoría de la mímesis aristotélica y en términos de la tradición de la teoría del arte como estética, lo que en rigor haría imposible hablar de la verdad en el cine, reduciendo la atribución de verdad a lo sumo, solo para la televisión que Gustavo Bueno llama "formal" (esto es, en directo"), hablaremos de cine propio o cine impropio. Decimos que una película de cine es propia cuando lo que vemos en ella es congruente de modo más o menos verosímil con nuestra experiencia del mundus adspectabilis, no con nuestras creencias, sino con lo que no es dado efectivamente ver. Cuando se habla de creencias, se insiste en la idea de creer en lo que no se ve, etc., pero en el cine se consigue precisamente eso, hacer visible lo que no puede ser visto en nuestra realidad cotidiana, en nuestra experiencia cotidiana del mundus adspectabilis. Pues bien, diríamos que si se hace visible en el cine algo que no es congruente con nuestra experiencia cotidiana, diremos que se trata de un cine impropio, mientras que si lo que vemos grabado en la película resulta congruente podemos considerarlo propio. La congruencia del cine con nuestra experiencia del mundo es evidente que tiene diversos grados y está en función, por tanto, del público, lo que por otra parte es absolutamente necesario y lógico, como decía Hitchcock. Al fin y al cabo, un público de historiadores necesariamente impondrá muchas más restricciones a la congruencia de la historia contada en

\footnotetext{
9 Para estas cuestiones conviene revisar Bueno, Televisión; también puede consultarse Bueno, Telebasura o Bueno, La fe.
} 
el cine con relación a sus conocimientos históricos, mientras que para un profano en Historia que el Coliseo aparezca reconstruido antes de su efectiva construcción histórica puede pasar perfectamente desapercibido. La congruencia supone también la posibilidad de que una industria cinematográfica suficientemente potente, combinada con un sistema educativo nefasto contribuya a que los ciudadanos se acaben creyendo patrañas no ya de ciertos matices históricos, sino verdaderas barbaridades históricas y morales: que la II Guerra Mundial la ganaron los EEUU, o que Hitler era en el fondo un gran hombre, o que Francisco Franco era un tonto a las tres, o que las pirámides de Egipto las hicieron los extraterrestres, o que Stalin era el diablo. La capacidad del cine para manipular y engañar no está solo en que pueda reconstruir y hacer visible. Pero, en general, diríamos que no solamente por la Historia, sino por nuestra experiencia cotidiana, nos resultará imposible ontológicamente, impropio diríamos, la existencia de un vampiro, o que un hombre pueda volar, o que una niña pueda girar 360 grados su cabeza sin experimentar ningún problema fisiológico.

Por tanto, y a pesar de las ambigüedades y restricciones que cabe hacer a nuestra experiencia cotidiana del mundus adspectabilis, una experiencia cotidiana no individual, sino fundamentalmente social, lo que otorga también un sentido ontológico preciso al hecho de ver el cine en salas llenas de gente, cabe distinguir en general un tipo de cine propio, congruente, no decimos "adecuado" a la historia que se cuenta, sino congruente con el mundo en el que vivimos y con la experiencia que nos envuelve, y un cine impropio. Puesto que el buen cine, propio o impropio, siempre ha de resultar en principio verosímil, que es en donde reside su propia verdad gnoseológica.

En general, podríamos decir, a lo sumo, que estas tres perspectivas podrían corresponder en cierto modo con tres formas de cine en función de la configuración material del escenario. Así, cuando una película es histórica, o trata un tema histórico, necesariamente procurará cumplir el trámite adecuacionista y procurará valorarse la importancia de la película en función de si la simulación mimética recrea adecuadamente la historia acontecida. De la misma manera, el descripcionismo podría corresponder con el cine que aborda temas 
de presente, por así decir, en donde sería posible sin demasiados problemas hacer realidad el programa de Erice, un cine testimonio tal y como lo concibiera, por ejemplo, Ziga Vertov. Igualmente, podría entenderse que el enfoque teoreticista, aquel en el que el director tiene libertad para inventarse situaciones, etc., correspondería en gran medida con el cine que trata temas "futuros" por así decir, lo que podría ocurrir, o incluso lo que no podría ocurrir: el cine fantástico o el cine de ciencia ficción. Esta clasificación podría resultar apropiada si no fuera porque en todo caso cabe enfocar el problema de la verdad en todo cine posible, en toda construcción artística, por así decir, porque el cine es siempre construcción y porque está involucrado con la verdad más allá de la adecuación.

La propuesta de La ventana indiscreta es que efectivamente las artes miméticas, y el cine en particular, construyen verdades, y esas verdades son las propias obras de arte en su concreción dialéctica como integración totalizadora de sus partes materiales y formales en una unidad artística. El cierre categorial entiende la verdad como la identidad sintética de las partes formales a través de las partes materiales, pero de manera que se han segregado las operaciones. Es claro que en las artes las operaciones no se segregan, sino que se miman, se recrean, se ponen en presente dramático. Pero en la medida en que constituyen una acción finalista, cabe decir que la identidad sintética aquí ejercida es procesual, por tanto, operatoria, pero con un resultado que supone la concreción de un objeto artístico. Esta verdad solo se manifiesta como verosimilitud, la verosimilitud que cabe atribuir a la integración de las partes en una unidad y que depende de la propia concreción objetual, pero también de la propia disposición de los espectadores, de su conocimiento. Así, en el cine, la verosimilitud de una película supone la composición completa de sus partes en una unidad, como decía Eisenstein, pero su verosimilitud también está en función de los espectadores (Hitchcock), por tanto es ciertamente difusa. Cuando en 1970 apareció Genie, "la niña salvaje", así llamada, en California, los psicólogos que la atendían hicieron un pase privado de la película de Truffaut, El niño salvaje, para estudiar el caso que tenían presente. Truffaut ahí ofrecía, como artista, un análisis en presente dramático 
de un conflicto finalista acaecido en Francia durante el siglo XIX, que sirvió como informe para los psicólogos. Cuando un historiador ve una película histórica, la verosimilitud que puede atribuir a la recreación mimética de la acción tendrá muchos más puntos de cierre que la de un espectador no experto, etc. El cierre categorial, la identidad sintética procesual de la verosimilitud es, por tanto, más ambigua e indeterminada que los procesos de cierre categorial gnoseológicos propios de las ciencias alfa-operatorias, ${ }^{10}$ pero, no por ello menos efectiva para su campo correspondiente. Al fin y al cabo, también el "público" de las ciencias es variado.

\section{El cine en el ranking de las ciencias humanas}

Por tanto, las artes se aproximan a lo que Bueno ha llamado ciencias beta operatorias, ciencias en cuyos campos no se pueden segregar las operaciones, o en las que el proceso de segregación de las operaciones se alcanza solo relativamente, de tal manera que si llegase a alcanzarse una segregación total de las operaciones dejarían de ser ciencias beta operatorias, y por tanto dejarían, por así decir, de ser ciencias humanas. ${ }^{11}$

Partimos, por tanto, de la clasificación de niveles operatorios que propone Gustavo Bueno en su teoría del cierre categorial para determinar la ambigüedad gnoseológica constitutiva de las ciencias humanas. En esta teoría se propone una clasificación de, digamos, niveles operatorios que son los siguientes que vamos a estudiar con un ejemplo ficticio pero suficientemente explícito. Tomemos, un ejemplo. Manolis Glezos subió a la Acrópolis y arrió la bandera nazi en medio de la ocupación alemana. Ese acto puede quedar recogido como simulación mimética de diversos modos.

\footnotetext{
${ }^{10}$ Sobre las cuestiones relativas a las ciencias alfa-operatorias y beta-operatorias es necesario consultar el ensayo de Gustavo Bueno, "En torno al concepto...".

${ }^{11}$ Véase nota anterior.
} 
Modo B2: Imaginemos una cámara de televisión grabando y emitiendo en directo la hazaña, siguiendo en todo momento la acción en tanto que está ocurriendo. Evidentemente, la televisión no existía entonces, lo que significa que estos diferentes niveles operatorios de las simulaciones miméticas solo han podido irse decantando históricamente con el propio desarrollo de las tecnologías audiovisuales, y concretamente con la televisión formal.

Modo 2B1: Ahora estamos en la situación en la que el realizador de televisión graba el acontecimiento tomando varias perspectivas, grabando testimonios, opiniones, reconstruyendo los hechos, viajando al lugar, grabando lo que ha quedado de su vida y de su hazaña. Luego, el realizador monta un documental que recoge la acción en el contexto en el que se dio. Esto es un documental montado sobre la grabación en directo.

Modo 1B1: En esta situación tendríamos que el equipo de grabación utiliza actores y busca un escenario cómodo para grabar la acción y recrearla a su modo, poniendo la cámara donde mejor le conviene, buscando el detalle, generando suspense, introduciendo un montaje, etc. Estamos ante una película digamos propia en sentido vulgar y clásico.

Modo 2alfa2: En esta situación tendríamos la misma situación pero cargada ya de detalles que se imponen sobre las operaciones dándole un sentido cada vez más definido: pongamos por caso que usamos un color blanco para representar a los héroes, un color negro para los malvados, usamos un tipo de contrapicados y picados con intención moralizante, y generamos una tragedia de buenos y malos que desborda la pretensión de construir una acción en presente dramático, porque estas acciones quedan subsumidas en el contraste moral que se pretende. En este nivel alcanzamos un tipo de cine propagandístico característico que subordina las operaciones finalistas estudiadas bajo un paradigma moral alfa operatorio.

Modo 1alfa2: Cuando en el contexto de la acción dramática introducimos elementos claramente impropios, como acciones invero- 
símiles, o acciones imposibles que pueden servir para convertir a Manolis Glezos en un héroe legendario conformado por un patrón como el del héroe universal de Joseph Campbell.

Vemos así que cuanto mayor es el grado de abstracción de las operaciones, más nos aproximamos al ámbito del cine impropio, mientras que el cine propio se mantiene claramente en la zona beta operatoria. Finalmente, diremos que estas mismas consideraciones serían aplicables a las diferentes artes miméticas.

Desde el cierre categorial, el entorno escénico se presenta como contexto determinante de la acción dramática; y la acción, como la disposición finalista que organiza el todo y le otorga un sentido; una pose, una disposición narrativa, una explicación, un teorema. Una obra de arte es a las artes lo que un teorema es a las ciencias. $\mathrm{Y}$ los teoremas artísticos se entrelazan al igual que ocurre en las ciencias. Un cuadro puede ser el motivo de una acción dramática, lo mismo que una novela o una escultura. Cuando Angelopoulos, en La mirada de Ulises, reconstruye acciones a partir de cuadros de Magritte, está incorporando estos teoremas de la pintura en el campo gnoseológico del cine. El laboratorio del cine es el estudio en el que se recrea la acción; el director y su equipo se constituyen como un verdadero equipo de investigación y en sus películas ofrecen teorías completas acerca de modelos operatorios finalistas. $\mathrm{Al}$ igual que los sucesos astronómicos solo se proyectan en los mapas celestes, así también solo en las obras de arte se proyectan los sucesos poéticos.

\section{Obras consultadas}

Adrados, Francisco. Fiesta, comedia y tragedia. Barcelona: Planeta, 1972. Impr.

Balló, Jordi y Xavier Pérez. La semilla inmortal. Los argumentos universales en el cine. Barcelona: Anagrama, 1997. Impr.

Bazín, André. ¿Qué es el cine? Madrid: Rialp, 2014. Impr.

Bueno, Gustavo. La idea de ciencia desde la teoría del cierre categorial. Santander: Universidad Internacional Menéndez Pelayo, 1976. Impr. 
—_. "Reliquias y relatos". El Basilisco 1 (1978): 5-16. Impr.

_. "En torno al concepto de 'Ciencias Humanas'. La distinción entre metodologías alfa-operatorias y beta-operatorias". El Basilisco 2 (1978): 12-46. Impr.

—. El individuo en la historia. Oviedo: Universidad de Oviedo, 1980. PDF.

- Teoría del cierre categorial. 5 vols. hasta la fecha. Oviedo: Pentalfa, 1992-. Impr.

_. "Estado e historia", El Basilisco 2a. época, n 11 (1992):

3-27. Impr.

- ¿Qué es la ciencia? Oviedo: Pentalfa, 1995. Impr.

—. El sentido de la vida. Oviedo: Pentalfa, 1996. Impr.

- Televisión: Apariencia y Verdad. Barcelona: Gedisa, 2000. Impr.

—. Telebasura y democracia. Barcelona: Ediciones B, 2002. Impr.

- Curso de Filosofía de la Música. Fundación Gustavo Bueno, 2007. Web. 23 sep. 2015.

—. La fe del ateo. Madrid: Temas de hoy, 2007. Impr.

Gubern, Román. Máscaras de la ficción. Barcelona: Anagrama, 2002. Impr.

Huerga Melcón, Pablo. "Breviario de introducción al Materialismo Filosófico. La doctrina del Hiperrealismo, Epistemología, Gnoseología y Ontología”. Nómadas 18. 2 (2008): 195-209. PDF.

—. "La otra cara del Guernica". El Catoblepas 90 (2009): 13. Web. 23 sep. 2015.

Lessing, Gotthlod Ephraim. Laocoonte. Madrid: Tecnos, 1976. Impr. Sklovski, Viktor. Cine y lenguaje. Barcelona: Anagrama, 1971. Impr. 